\section{In Vitro Germination and Initial Seedling Development of Krantz Aloe by Smoke- saturated Water and Seed Imbibition}

\author{
Claudia A. Espinosa-Leal ${ }^{1}$ and Silverio Garcia-Lara ${ }^{1}$
}

ADDITIONAL INDEX wORDs. Aloe arborescens, germination pretreatment, $\mathrm{KAR}_{1}$, karrikinolide, seed germination, seed water soaking

SuMMARY. Krantz aloe (Aloe arborescens) is one of two aloe species currently used for the extraction of active ingredients that can be useful in the cosmetic and pharmaceutical industries. However, krantz aloe plants have been frequently collected from the wild, which is threatening wild populations. In vitro tissue culture would allow the growth of krantz aloe under controlled conditions, optimizing the production of active ingredients without risk to wild populations. The establishment of cultures from krantz aloe plant explants has proved difficult as a result of the long response times of the explants and their release of polyphenols. Krantz aloe seeds are not commonly used as a means of propagation because of their low germination percentages. The objective of this study was to evaluate the effects of seed imbibition (SI) with water and the addition of smoke-saturated water (SSW) to the culture medium on the in vitro germination and initial seedling development of krantz aloe. Seeds were germinated in vitro in axenic conditions. The treatments used were the addition of $10 \%$ SSW to the culture media, SI, and a combination of both ( $10 \%$ SSW + SI). Daily germination was recorded and gross morphology was measured after 1 month of culture establishment. The maximum germination percentage (GP) was achieved when $10 \%$ SSW was in the medium $(97.2 \%)$, followed by the combined application of $10 \%$ SSW + SI $(96.6 \%)$, both of which were almost $30 \%$ greater and significantly different from that of the control (69.4\%). SI had an $83.3 \%$ GP. No significant differences were observed among treatments in any of the observed development parameters (leaf and root length and number). Taken together, these findings show that the use of SSW improves the in vitro germination of krantz aloe without affecting seedling development, indicating preliminarily that SSW represents a useful in vitro germination promoter for this species.

$\mathrm{T}$ rue aloe (Aloe vera) and krantz aloe (Aloe arborescens) are currently being used for the extraction of cosmetic and nutraceutical active ingredients (Cardarelli et al., 2017; Espinosa-Leal and GarciaLara, 2019). Krantz aloe has a wide geographical distribution in the African continent, with populations in South Africa, Botswana, Swaziland, Lesotho, Mozambique, Zimbabwe, Mapaura and Timberlake, and

Received for publication 1 May 2020. Accepted for publication 3 June 2020

Published online 27 July 2020

${ }^{1}$ BioScience Unit, EIC, Tecnologico de Monterrey, Campus Monterrey, Avenue Eugenio Garza Sada 2501, Monterrey, N.L., 64849, México

This work was supported by grants from the Research Nutriomics Chair Funds and CAT-005 of Tecnologico de Monterrey, as well as postdoctoral fellowships presented to C.A.E.-L. by CONACyT, Mexico, and Tecnologico de Monterrey.

C.A.E.-L. is the corresponding author. E-mail: claudia_espinosa@tec.mx.

This is an open access article distributed under the $\mathrm{CC}$ BY-NC-ND license (https://creativecommons.org/ licenses/by-nc-nd $/ 4.0 /$ ).

https://doi.org/10.21273/HORTTECH04643-20
Malawi. Although krantz aloe is common within its range, human activity has caused a negative impact on populations (Smith et al., 2008). Wild populations of aloe species are currently threatened as a result of their continuous collection for transplantation to private gardens or the extraction of active ingredients (Maundu et al., 2006). Conventional propagation using lateral shoots and rhizome cuttings is not able to fulfill the increasing market demand for aloe (Cristiano et al., 2016).

In vitro tissue culture represents a promising alternative to wild collections of krantz aloe plants and conventional propagation by allowing the production of multiple plants for their reintroduction to the wild and fields, and production of active metabolites to be optimized (EspinosaLeal et al., 2018). Although some reports exist on the in vitro tissue culture of krantz aloe (Bedini et al., 2009; Cardarelli et al., 2017; Kawai et al., 1993), the establishment of cultures from plant explants has proved difficult because of the long response times of the explants and their release of polyphenols, resulting in the need for constant subcultures (Bedini et al., 2009).

Seeds are an alternative explant for in vitro culture establishment. True aloe seeds are not commonly used as a means of propagation (traditional and in vitro) because of their scarcity in nature and low GPs of $0 \%$ to $25 \%$ (traditional) and $60 \%$ to $70 \%$ (in vitro) (Cristiano et al., 2016). Studies have investigated the optimization of germination conditions for bitter aloe (Aloe ferox) and krantz aloe in petri dishes without substrate and with filter paper, which have shown that the use of karrikinolide $\left(\mathrm{KAR}_{\mathrm{l}}\right)$ rich SSW either as a priming treatment or a watering solution promotes seed germination (Bairu et al., 2009; Kulkarni et al., 2013). Studies have demonstrated that SSW can also promote seedling vigor, including leaf and root length and number (Demir et al., 2018). Hydration of seeds before sowing is another method for improving germination (Demir et al., 2018; Khan, 1992). However, the effect of SSW and SI, separately and combined, on the in vitro germination of krantz aloe under aseptic conditions using Murashige and Skoog (MS) culture media (Murashige and Skoog, 1962) as a standard substrate has not been investigated previously. Therefore, the objective of this work was to evaluate the effect of SI with water and the addition of SSW to the culture media on the in

\begin{tabular}{llll}
\hline $\begin{array}{l}\text { Units } \\
\text { To convert U.S. to SI, } \\
\text { multiply by }\end{array}$ & U.S. unit & SI unit & $\begin{array}{l}\text { To convert SI to U.S., } \\
\text { multiply by }\end{array}$ \\
\hline 29.5735 & $\mathrm{fl} \mathrm{oz}$ & $\mathrm{mL}$ & 0.0338 \\
0.3048 & $\mathrm{ft}$ & $\mathrm{m}$ & 3.2808 \\
2.54 & inch $(\mathrm{es})$ & $\mathrm{cm}$ & 0.3937 \\
25.4 & inch $(\mathrm{es})$ & $\mathrm{mm}$ & 0.0394 \\
28.3495 & $\mathrm{OZ}$ & $\mathrm{g}$ & 0.0353 \\
$\left({ }^{\circ} \mathrm{F}-32\right) \div 1.8$ & ${ }^{\circ} \mathrm{F}$ & ${ }^{\circ} \mathrm{C}$ & $\left({ }^{\circ} \mathrm{C} \times 1.8\right)+32$
\end{tabular}


vitro germination and initial seedling development of krantz aloe.

\section{Materials and methods}

Seeds (152 total) were obtained from the mature fruit (eight total) of two different 4-year-old krantz aloe plants growing at an altitude of $2300 \mathrm{~m}$ (lat. $19.483^{\circ} \mathrm{N}$, long. $98.903^{\circ} \mathrm{W}$ ) provided by Bioimpulsora Company (Texcoco, Mexico) in Mar. 2018. The seeds were stored at $4{ }^{\circ} \mathrm{C}$ until the start of the experiment on 12 Apr. 2018.

An SSW solution was prepared according to the method described by Coons et al. (2014), with some modifications-namely, the reduction of the initial plant cellulose. Briefly, $36.5 \mathrm{~g}$ of filter paper (No. 1; Whatman, Little Chalfont, UK) was cut into strips and placed inside a bee smoker (Mieles Tecnología, Merida, México), filling it to threequarter capacity. The paper at the bottom of the smoker was then ignited and covered with more paper until smoke was produced. A heatresistant hose was attached to the opening of the bee smoker and was connected to a Kitasato flask containing $500 \mathrm{~mL}$ distilled water, and a pressure pump-inducing vacuum was used to draw the smoke through the water. The bellows on the bee smoker were pumped occasionally to allow for the continuation of combustion. As the filter paper burned, more was added to the smoker until the initial sample was fully combusted. The system was then allowed to cool for $15 \mathrm{~min}$. The saturated smoke solution was transferred to an amber bottle and stored in a refrigerator at $4{ }^{\circ} \mathrm{C}$ until later use (about 1 month).

The germination experiments were performed three times independently with seeds from the same batch of fruit. Because of the scarcity of seeds, each experiment consisted of four treatments that used four glass jars (capacity, $110 \mathrm{~mL}$ ) each and a final treatment with 12 seeds per treatment. The treatments were as follows: treatment 1, 10\% SSW and 1:10 MS $10 \%$ SSW; treatment 2 (SI), seeds imbibed in distilled water for $16 \mathrm{~h}$ (SI) and placed in 1:10 MS; and treatment $3(10 \% \mathrm{SSW}+\mathrm{SI})$, seeds imbibed in water for $16 \mathrm{~h}$ and placed in $1: 10 \mathrm{MS} 10 \% \mathrm{SSW}$. As a control, seeds were placed in 1:10 MS.

The seeds were surface-disinfected using the following procedure. Seeds were washed under running water, submerged in a soap-water $1 \%$ (by volume) liquid detergent (Salvo PA00186821; Procter \& Gamble, Cincinnati, $\mathrm{OH}$ ) and $0.5 \%$ (by volume) nonionic surfactant $\left(\right.$ Tween $^{\circledR} \quad 20$; Hycel, Zapopan, México) for 15 min, washed in sterile distilled water, immersed in a $15 \%(\mathrm{v} / \mathrm{v})$ commercial sodium hypochlorite (Clorox, Oakland, CA) solution for $20 \mathrm{~min}$, and finally washed with sterile distilled water under a laminar flow hood (Purifier class II biosefty cabinet; LABCONCO, Kansas City, MO). Three seeds were then placed in each glass jar with $20 \mathrm{~mL}$ l:10 (w/w) MS (M5519; Merck, Darmstadt, Germany) (Bairu et al., 2009; Murashige and Skoog, 1962) with 7\% agar (A296; PhytoTechnology Laboratories, Shawnee Mission, KS) using either distilled water or $10 \%$ SSW as a solvent.

Cultures were placed in a controlled-environment chamber (Signature Diurnal Growth Chamber model 2015; VWR International, Radnor, PA) at $25^{\circ} \mathrm{C}$ with a $12: 12$-h photoperiod [ $12 \mathrm{~h}$ of light at $89.1 \mu \mathrm{mol} \cdot \mathrm{m}^{-2} \cdot \mathrm{s}^{-1}$ (Dual-Range Traceable Light Meter; Control Co., Friendswood, TX) and $12 \mathrm{~h}$ of complete darkness]. The seeds were examined every $24 \mathrm{~h}$ for $15 \mathrm{~d}$. Germination was considered complete when the seedcoat had broken and a radicle of $\approx 2 \mathrm{~mm}$ in length had emerged (Bairu et al., 2009). Germination initiation (GI) was counted when at least one of the seeds germinated; germination end (GE) was considered as the last day

Table 1. Germination parameters of in vitro culture of krantz aloe in 1:10 Murashige and Skoog culture media with a 12-h (light) photoperiod and at a $25^{\circ} \mathrm{C}\left(77.0^{\circ} \mathrm{F}\right)$ constant air temperature in a controlled-environment chamber.

\begin{tabular}{|c|c|c|c|c|}
\hline \multirow[b]{2}{*}{ Treatment $^{\mathrm{z}}$} & $\mathrm{CVG}^{\mathrm{y}}$ & GRI $(\% / d)^{x}$ & GI $(d)^{w}$ & $\mathrm{GE}(\mathrm{d})^{\mathrm{v}}$ \\
\hline & \multicolumn{4}{|c|}{$($ mean $\pm S D)$} \\
\hline $\mathrm{C}$ & $13.5 \pm 2.3 \mathrm{NS}$ & $46.6 \pm 3.9 \mathrm{NS}$ & $6.3 \pm 0.9 \mathrm{NS}$ & $12.7 \pm 7.3 \mathrm{NS}$ \\
\hline $10 \%$ SSW & $13.1 \pm 1.6 \mathrm{NS}$ & $63.2 \pm 18.6 \mathrm{NS}$ & $5.7 \pm 0.5 \mathrm{NS}$ & $9.7 \pm 1.7 \mathrm{NS}$ \\
\hline SI & $16.7 \pm 3.0 \mathrm{NS}$ & $73.2 \pm 8.6 \mathrm{NS}$ & $5.0 \pm 0.0 \mathrm{NS}$ & $7.3 \pm 1.7 \mathrm{NS}$ \\
\hline $10 \%$ SSW + SI & $15.4 \pm 3.0 \mathrm{NS}$ & $77.9 \pm 15.4 \mathrm{NS}$ & $5.3 \pm 0.5 \mathrm{NS}$ & $8.3 \pm 2.1 \mathrm{NS}$ \\
\hline
\end{tabular}

${ }^{\mathrm{z}} \mathrm{C}=$ control; SSW $=10 \%$ smoke-saturated water; $\mathrm{SI}=$ seed imbibition. yCoefficient of velocity of germination $(\mathrm{CVG})=\left(\sum_{i=1}^{k} f_{i} / \sum_{i=1}^{k} f_{i} x_{i}\right) 100$, where $f_{i}$ is the number of seeds newly
germinated

on day $i, x_{i}$ is the number of days from sowing, and $k$ is the last day of germination.

${ }^{\mathrm{x}}$ Germination rate index $(\mathrm{GRI})=\sum_{i=1}^{k}\left(G P_{i}\right) 100 / x_{i}$, where $G P_{i}$ is the germination percentage on day $i, x_{i}$ is the number of

days from sowing, and $k$ is the last day of germination.

wFirst day of germination (counted when at least one of the seeds germinated).

'Last day of germination (the last day a seed germinated for each treatment).

$\mathrm{GI}=$ germination initiation; $\mathrm{GE}=$ germination end.

Ns, Nonsignificant at $P<0.05$ via ANOVA $(\mathrm{n}=36)$. 
difference was found. All data processing and analyses were conducted using Minitab Express (Minitab, State College, PA) with a $5 \%$ significance level.

\section{Results and discussion}

No significant difference was found between the treatments with regard to the timing of GI or GE (Table 1). Bairu et al. (2009) found previously that the in vitro germination of bitter aloe was very erratic, with germination starting on day 10 and ending more than 1 month after sowing. By contrast, krantz aloe presented shorter times to GI and GE. A study by Demir et al. (2018) found that seed priming with SSW produced a uniform germination in pepper (Capsicum annuum) seeds, both mature and immature. SSW and/or $\mathrm{KAR}_{1}$ was involved in the breaking of seed dormancy and the promotion of embryonic development (Demir et al., 2018; van Staden et al., 2006).

The only germination parameter affected by the treatments was GP (Fig. 1). The GP, $10 \%$ SSW and $10 \%$ SSW + SI were significantly greater than the control, whereas SI was similar to the control, $10 \% \mathrm{SSW}$, and $10 \%$ SSW + SI. The maximum GP obtained (mean $\pm \mathrm{SD}$ ) for $10 \% \mathrm{SSW}$ was $97.2 \% \pm 4.8 \%$, followed by $10 \%$ SSW + SI $(96.7 \% \pm 5.8 \%)$, both of which were almost $30 \%$ greater than the control $(69.4 \% \pm 4.8 \%)$ (Fig. 1). Several studies have demonstrated that smoke can promote the in vivo germination of many different species of plants, including bitter and krantz aloe (Bairu et al., 2009; Kulkarni et al., 2013). The application of SSW as a watering solution in petri dishes resulted in $80 \%$ GP in bitter aloe (Bairu et al., 2009) and 60\% GP in krantz aloe (Kulkarni et al., 2013), both of which were greater than control levels. In our study, a GP of more than $95 \%$ was achieved in the treatments that included SSW. We suspect these high levels of GP, compared with the previous studies, may be explained by the greater concentration of SSW used (10\% in comparison with $0.2 \%$ used before).

The SI did not improve the in vitro germination of krantz aloe, which is in agreement with the findings of Santini et al. (2017) for two cactus species (Cactaceae). Because imbibition improves and synchronizes germination by hydrating the seeds to begin the preliminary process of germination (Demir et al., 2012; Khan, 1992), this finding suggests that the humidity conditions were sufficient to remove the need for prior seed hydration, as experienced by Gupta et al. (2020), who found that seeds exposed to room temperature initiated the process of germination. Seedcoat structure is a determinant of the need for seed imbibition before soaking. In general, a permeable or "soft" seedcoat absorbs water more formed a thin layer of water that

easily, opposite to more impermeable or "hard" seedcoats that do not imbibe water even after days of soaking (Ma et al., 2004, Shao et al., 2007; Varela and Albornoz, 2013). Krantz aloe seedcoat can then be classified as permeable. No other germination parameters were affected by the treatments in our study.

A representative photograph of krantz aloe seedlings after $30 \mathrm{~d}$ is shown in Fig. 2. No significant difference was found in the gross morphology of the seedlings among treatments (Table 2). Initial seedling development was unaffected by the

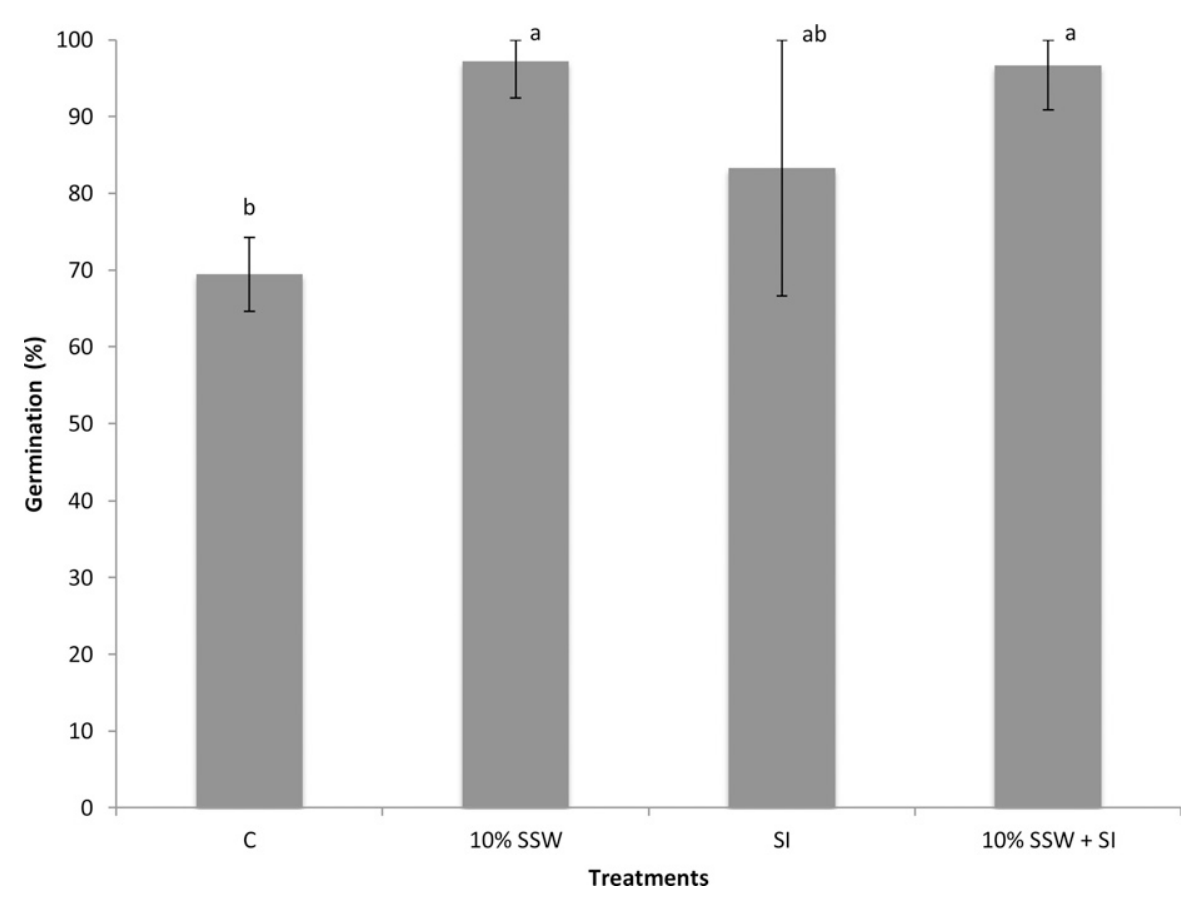

Fig. 1. Effects of seed imbibition (SI) and smoke-saturated water (SSW) on the in vitro germination percentage of krantz aloe in 1:10 Murashige and Skoog culture media with a 12 -h (light) photoperiod and at a $25^{\circ} \mathrm{C}\left(77.0^{\circ} \mathrm{F}\right)$ constant air temperature in a controlled-environment chamber; $\mathrm{C}=$ control, $10 \% \mathrm{SSW}=$ addition of $10 \%$ smoke saturated water to culture media, SI = seed imbibition for $16 \mathrm{~h}$. Data are expressed as mean \pm SD. Values with different letters are significantly different via Tukey's test at $P<0.05(\mathrm{n}=36)$.

Table 2. Gross morphology of in vitro krantz aloe plantlets after 1 month of initial culture establishment in 1:10 Murashige and Skoog culture media with a 12-h (light) photoperiod and at a $25^{\circ} \mathrm{C}\left(77.0^{\circ} \mathrm{F}\right)$ constant air temperature in a controlled-environment chamber.

\begin{tabular}{lrccc}
\hline & Leaves (no.) & Roots (no.) & Leaf length $(\mathbf{c m})^{\mathrm{y}}$ & Root length $(\mathbf{c m})$ \\
\cline { 2 - 5 } Treatment $^{\mathrm{z}}$ & \multicolumn{4}{c}{$($ mean \pm SD) } \\
\hline C & $2.7 \pm 0.5 \mathrm{NS}$ & $3.4 \pm 0.7 \mathrm{NS}$ & $1.4 \pm 0.4 \mathrm{NS}$ & $1.2 \pm 0.4 \mathrm{NS}$ \\
$10 \% \mathrm{SSW}$ & $2.5 \pm 0.7 \mathrm{NS}$ & $3.4 \pm 1.4 \mathrm{NS}$ & $1.1 \pm 0.3 \mathrm{NS}$ & $0.7 \pm 0.6 \mathrm{NS}$ \\
SI & $2.6 \pm 0.5 \mathrm{NS}$ & $2.7 \pm 1.4 \mathrm{NS}$ & $1.3 \pm 0.5 \mathrm{NS}$ & $0.9 \pm 0.6 \mathrm{NS}$ \\
$10 \% \mathrm{SSW}+\mathrm{SI}$ & $3 \pm 0.4 \mathrm{NS}$ & $3.1 \pm 0.9 \mathrm{NS}$ & $1.3 \pm 0.3 \mathrm{NS}$ & $0.7 \pm 0.5 \mathrm{NS}$ \\
\hline
\end{tabular}

${ }^{\mathrm{z}} \mathrm{C}=$ control; $10 \% \mathrm{SSW}=10 \%$ smoke-saturated water; $\mathrm{SI}=$ seed imbibition.

${ }^{\mathrm{y}} \mathrm{l} \mathrm{cm}=0.3937$ inch.

Ns, Nonsignificant at $P<0.05$ via analysis of variance $(\mathrm{n}=36)$. 


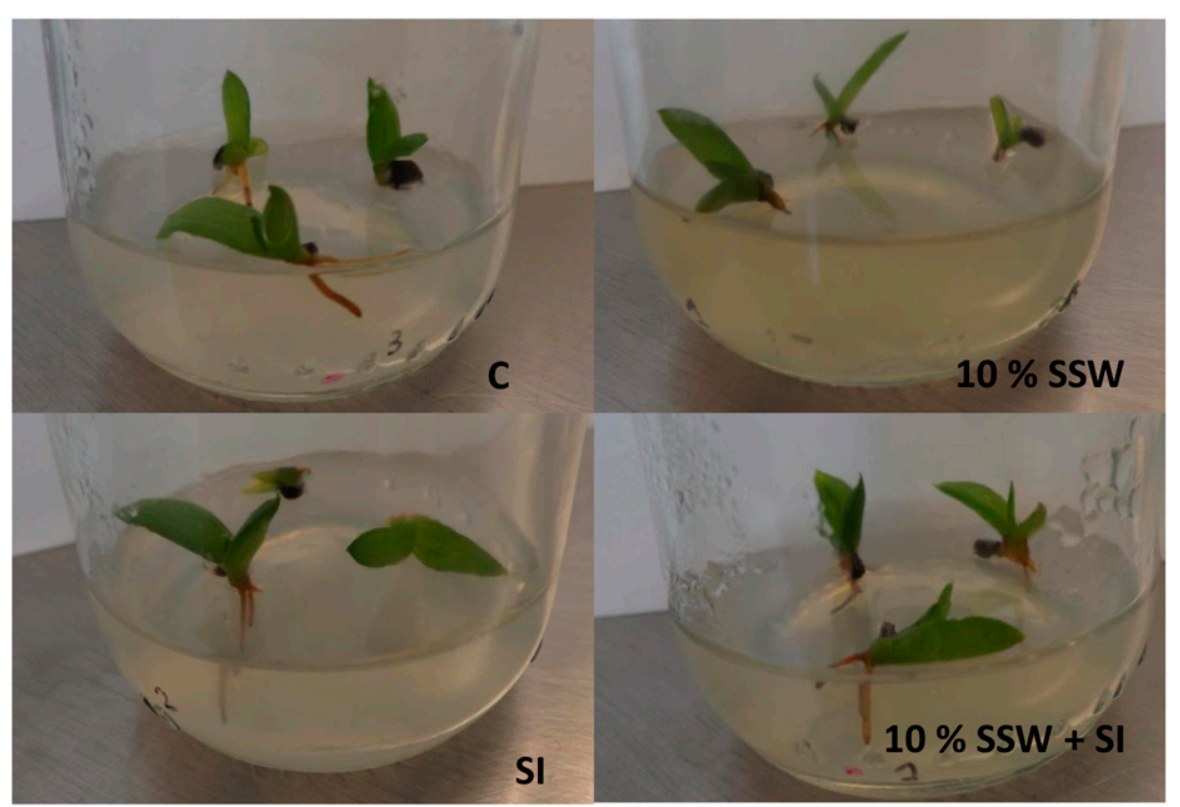

Fig. 2. Representative photograph of krantz aloe seedling after 1 month of growth in vitro in 1:10 Murashige and Skoog culture media with a 12-h (light) photoperiod and at a $25^{\circ} \mathrm{C}\left(77.0{ }^{\circ} \mathrm{F}\right)$ constant air temperature in a controlledenvironment chamber; $\mathrm{C}=$ control, $10 \%$ SSW = addition of $10 \%$ smoke saturated water to culture media, $\mathrm{SI}=$ seed imbibition for $16 \mathrm{~h}$.

addition of SSW to the culture medium, which contrasts with the findings of Chumpookam et al. (2012), who discovered that seedlings of papaya (Carica papaya) treated with $1 \%$ to $10 \%$ SSW exhibited significant increases in all growth parameters compared with the control. Bairu et al. (2009) found previously that bitter aloe seedlings develop better in the presence of culture medium containing low salt concentrations (1:10 MS culture media). Therefore, it is possible the addition of SSW to the culture medium altered the solute concentration, preventing any improvement in overall seedling growth for krantz aloe. However, we did not measure the salt content of the culture media.

Krantz aloe is a commercially important plant that is becoming increasingly threatened in the wild. The species is currently included in the Convention on International Trade in Endangered Species of Wild Fauna and Flora (CITES, 2019) Appendix II, and is considered vulnerable in certain regions and occurs in protected areas within its range (Martínez Richart, 2019). Hence, a need exists for the development of new cultivation methods to ensure the continued availability of its products. The addition of SSW to the culture medium improved the in vitro
GP for krantz aloe while having no effect on seedling development, suggesting it is an excellent promoter of in vitro germination for this species. Thus, SSW treatment would make the use of seeds for the establishment of in vitro tissue culture a viable option for this species; however, further work is needed to verify this report. The plantlets obtained by this process could be further exploited to obtain large-scale production of uniform, healthy plantlets that can later be used by the market (Cristiano et al., 2016; Gantait et al., 2014).

\section{Literature cited}

Bairu, M.W., M.G. Kulkarni, R.A. Street, R.B. Mulaudzi, and J. van Staden. 2009. Studies on seed germination, seedling growth, and in vitro shoot induction of Aloe ferox Mill., a commercially important species. HortScience 44:751-756.

Bedini, C., R. Caccia, D. Triggiani, A. Mazzucato, G.P. Soressi, and A. Tiezzi. 2009. Micropropagation of Aloe arborescens Mill: A step towards efficient production of its valuable leaf extracts showing antiproliferative activity on murine myeloma cells. Plant Biosyst. 143:233-240.

Cardarelli, M., Y. Rouphael, M. Pellizzoni, G. Colla, and L. Lucini. 2017. Profile of bioactive secondary metabolites and antioxidant capacity of leaf exudates from eighteen Aloe species. Ind. Crops Prod. 108:44-51.

Chumpookam, J., H.-L. Lin, and C.-C. Shiesh. 2012. Effect of smoke-water derived from burnt dry rice straw (Oryza sativa) on seed germination and growth of papaya seedling (Carica papaya cv. Tainung No. 2). HortScience 47:741744.

Convention on International Trade in Endangered Species of Wild Fauna and Flora (CITES). 2019. Appendices. Apendices I, II and III. 26 May 2020. $<$ ht tps://cites .org/eng/app / appendices.php $>$.

Coons, J., N. Coutant, B. Lawrence, D. Finn, and S. Finn. 2014. An effective system to produce smoke solutions from dried plant tissue for seed germination studies. Appl. Plant Sci. 2:1-5.

Cristiano, G., B. Murillo-Amador, and B. De Lucia. 2016. Propagation techniques and agronomic requirements for the cultivation of barbados aloe (Aloe vera (L.) Burm. F.): A review. Front. Plant Sci. 7:114.

Demir, I., E. Ozden, K.C. Yıldırım, O. Sahin, and J. van Staden. 2018. Priming with smoke-derived karrikinolide enhances germination and transplant quality of immature and mature pepper seed lots. S. Afr. J. Bot. 115:264-268.

Demir, I., I. Ozuaydin, F. Yasar, and J. van Staden. 2012. Effect of smoke-derived butenolide priming treatment on pepper and salvia seeds in relation to transplant quality and catalase activity. S. Afr. J. Bot. 78:83-87.

Esechie, H. 1994. Interaction of salinity and temperature on the germination of sorghum. J. Agron. Crop Sci. 172:194199.

Espinosa-Leal, C. and S. Garcia-Lara. 2019. Current methods for the discovery of new active ingredients from natural products for cosmeceutical applications. Planta Med. 85:535-551.

Espinosa-Leal, C.A., C.A. Puente-Garza, and S. García-Lara. 2018. In vitro plant tissue culture: Means for production of biological active compounds. Planta 248:1-18.

Gantait, S., U.R. Sinniah, and P.K. Das. 2014. Aloe vera: A review update on advancement of in vitro culture. Agr. Scand. B Soil Plant Sci. 64:1-12.

Gupta, S., J. Hrdlička, N. Ngoroyemoto, N.K. Nemahunguni, T. Gucký, O. Novák, M.G. Kulkarni, K. Doležal, and J. van Staden. 2020. Preparation and standardisation of smoke-water for seed germination and plant growth stimula- 
tion. J. Plant Growth Regulat. 39:338345 .

Kawai, K., H. Beppu, T. Koike, K. Fujita, and T. Marunouchi. 1993. Tissue culture of Aloe arborescens Miller var. natalensis Berger. Phytother. Res. 7:S5-S10.

Khan, A.A. 1992. Preplant physiological seed conditioning. Hort. Rev. 14:131-181.

Kulkarni, M.G., S.O. Amoo, L.S. Kandari, and J. van Staden. 2013. Seed germination and phytochemical evaluation in seedlings of Aloe arborescens Mill. Plant Biosyst. 148: $460-466$.

Ma, F., E. Cholewa, T. Mohamed, C.A. Peterson, and M. Gijzen. 2004. Cracks in the palisade cuticle of soybean seed coats correlate with their permeability to water. Ann. Bot. 94:213-228.

Martínez Richart, A.I. 2019. Aloe arborescens. The IUCN red list of threatened species 2019: E.T110688013A110688030. 27 Apr. 2020. <https://dx.doi.org/10.2305/IUCN.UK. 2019-1.RLTS.T110688013Al10688030.en>.
Maundu, P., P. Kariuki, and O. EyogMatig. 2006. Threats to medicinal plant species: An African perspective, p. 47-62. In: S. Miththapala (ed.). Conserving medicinal species: Securing a healthy future. IUCN: Ecosystems and Livelihoods Group, Asia, Colombo, Sri Lanka.

Murashige, T. and F. Skoog. 1962. A revised medium for rapid growth and bio assays with tobacco tissue cultures. Physiol. Plant. 15:473-497.

Nichols, M.A. and W. Heydecker. 1968. Two approaches to the study of germination data. Proc. Intl. Seed Testing Assn. 33:531-540.

Santini, B.A., M. Rojas-Aréchiga, and E. García Morales. 2017. Priming effect on seed germination: Is it always positive for cacti species? J. Arid Environ. 147:155-158.

Scott, S.J., R.A. Jones, and W.A. Williams. 1984. Review of data analysis methods for seed germination. Crop Sci. 24:11921199.
Shao, S., C.J. Meyer, F. Ma, C.A. Peterson, and M.A. Bernards. 2007. The outermost cuticle of soybean seeds: Chemical composition and function during imbibition. J. Expt. Bot. 58:1071-1082.

Smith, G., R.R. Klopper, and N.R. Crouch. 2008. Aloe arborescens (Asphodelaceae: Alooideae) and CITES. Haseltonia 14:189-198.

van Staden, J., S.G. Sparg, M.G. Kulkarni, and M.E. Light. 2006. Post-germination effects of the smoke-derived compound 3methyl-2H-furo [2,3-c]pyran-2-one and its potential as a preconditioning agent. Field Crops Res. 9:98-105.

Varela, R.O. and P.L. Albornoz. 2013. Morpho-anatomy, imbibition, viability and germination of the seed of Anadenanthera colubrina var. cebil (Fabaceae). Rev. Biol. Trop. 61:1109-1118. 